\title{
Derechos humanos y criminología: un vínculo ignorado
}

\author{
Mario Arroyo JuÁreZ*
}

\begin{abstract}
The aim of the paper is to analyze some of the existent contradictions within human rights discourse, particularly questioning the commonly accepted chronological approach that leads some authors to assume that there is a unique discourse on human rights. The short review of the genesis and historical development of this discourse has as main purpose to discuss a new typology that enables the study of the different human rights discourses that are currently performed. A second goal is to demonstrate how criminology and victimology, with some minor restrictions, are discourses that provide useful concepts for a better understanding and explanation of what takes place within the topic of human rights.
\end{abstract}

Keywords: criminology, human rights, Mexico, victimology.

\section{Resumen}

Este trabajo busca analizar algunas contradicciones presentes en el discurso de los derechos humanos, y cuestionar la visión cronológica generalmente aceptada, que lleva a algunos autores a suponer que existe sólo un discurso sobre los derechos humanos. La breve revisión sobre la génesis y el desarrollo histórico de dicho discurso tiene por objeto discutir una nueva tipología que permita distinguir y estudiar los diferentes discursos sobre derechos humanos que hoy se utilizan. Una segunda intención es demostrar cómo la criminología y la victimología, con restricciones menores, son discursos que pueden aportar conceptos útiles para una mejor comprensión y explicación de lo que acontece en torno a los derechos humanos.

Palabras clave: criminología, derechos humanos, México, victimología.

*Centro Internacional de Estudios sobre Seguridad. Correo-e: arroyomario@ 


\section{Crítica a las formas tradicionales de abordar los derechos humanos}

La idea convencional sostiene que el discurso de los derechos humanos ha pasado por cuatro diferentes etapas conocidas como generaciones. La primera, caracterizada por el establecimiento de derechos y libertades individuales, como los plasmados en la Declaración de Independencia de los Estados Unidos de Norteamérica o en la Declaración de los Derechos del Hombre y del Ciudadano en Francia en 1789. La segunda, surgida a finales del siglo XIX y desarrollada hasta mediados del siglo XX, caracteriza$\mathrm{da}$ por el establecimiento de derechos sociales en legislaciones locales e internacionales: derecho a la educación, a la salud, al trabajo, etcétera. La tercera, surgida después de la segunda posguerra y caracterizada por el establecimiento de derechos de grupos específicos considerados como vulnerables: niños, mujeres, minorías étnicas y víctimas de conflictos armados, entre otros. Se habla ya de una cuarta generación, caracterizada por el establecimiento de derechos ya no sólo a individuos o grupos, sino a pueblos enteros; por ejemplo, derecho a un desarrollo social justo y a un medio ambiente sano y equilibrado (Cfr. Álvarez, 1997: 14).

Sin embargo, asumir sin cuestionar esta cronología tiene implicaciones políticas y prácticas. Una consecuencia política negativa al aceptar el estudio de los derechos humanos a través del prisma generacional es que la historia aparece como un continuum de progreso donde cada nueva etapa es mejor que las anteriores; así la Declaración Universal de los Derechos Humanos de 1948 es vista como un innegable avance en comparación con la Declaración de los Derechos del Hombre y del Ciudadano de 1789. Un ejemplo del uso político que se da a esta visión cronológica de la historia la encontramos en las palabras de un ex presidente de la Comisión Nacional de Derechos Humanos (CNDH) cuando afirma que:

México ha tenido una hermosa tradición de reconocimiento y apoyo a los derechos humanos (...) Desde los bandos de Hidalgo hasta la Constitución del 5 de febrero de 1917, el tema del reconocimiento y vigencia efectiva de los derechos fundamentales del hombre se visualiza como un proceso continuo y siempre inacabado. De esa hermosa tradición los mexicanos podemos sentirnos legítimamente orgullosos (Madrazo, 1997: 16).

El problema al aceptar esta idea de progreso es que se dejan de lado, o se ocultan deliberadamente, las relaciones de poder in- 
mersas en el discurso de los derechos humanos. Al privilegiar el saber sobre el poder, esto es, al priorizar el contenido teórico de las declaraciones o legislaciones sobre sus implicaciones prácticas, se propicia que el discurso de los derechos humanos, lejos de ser un vehículo de protección para los individuos, se convierta en un instrumento legal para su dominación por parte de los Estados. Esto es posible porque los Estados al firmar convenios y tratados, o emitir legislaciones sobre derechos humanos se sitúan dentro de la norma legal, mientras que en la práctica violan, en ocasiones sistemáticamente, los derechos de sus ciudadanos amparados en esos mismos instrumentos legales o simplemente los ignoran.

Una expresión concreta del tipo de dominación legal a la que me refiero se ve claramente reflejada en el discurso de los derechos humanos que se utiliza en los organismos internacionales (Organización de las Naciones Unidas, Organización de Estados Americanos, Unión Europea, etcétera). Este discurso utiliza un lenguaje diplomático, deliberadamente ambiguo destinado a no ofender ni comprometer a nadie. Es un discurso diseñado para permitir que los países puedan interpretarlo según su conveniencia. Para ilustrar lo anterior, veamos algunos artículos de la Convención Americana sobre Derechos Humanos de 1969; el artículo 4 de esta convención establece que: "Toda persona tiene derecho a que su vida sea respetada" e inmediatamente acota: "En aquellos países que aún no han abolido la pena de muerte, ésta debe ser impuesta sólo para los delitos más serios y por medio de un juicio definitivo presentado por una corte competente y de acuerdo con una ley que establezca semejante castigo" (Ishay, 1997: 442). El artículo 13, por su parte, establece que: "Todo individuo tiene el derecho a la libertad de expresión y pensamiento", derecho que puede ser restringido cuando se trate de "respetar los derechos o reputación de otros" o "la protección de la seguridad nacional, el orden público, la salud o la moral públicas" (1997: 446). Lo que podemos concluir de la lectura e interpretación de estos artículos es que en su dimensión práctica, la Convención permite a los Estados firmantes privar de la vida a sus ciudadanos y coartar su libertad de expresión y pensamiento, siempre y cuando lo establezcan sus propias leyes.

El análisis de las ambigüedades y contradicciones que caracterizan al lenguaje de los derechos humanos tiene como propósito sugerir que el estudio de los derechos humanos, en tanto saber (convenciones, tratados, leyes, etcétera), es por sí solo una 
empresa ociosa. Es necesario analizar y comprender también su dimensión práctica. Una vez que se admite la necesidad de estudiar las dos dimensiones del discurso de los derechos humanos, es necesario realizar un análisis más detallado en tanto que no existe un solo discurso de los derechos humanos, sino varios. Como se verá, distinguir los diferentes tipos de discursos es de fundamental importancia, tanto en términos teóricos como prácticos.

\section{Tipología de discursos sobre derechos humanos}

Una clasificación alternativa y más útil que la visión generacional para el estudio de los derechos humanos es dividirlo de acuerdo con el tipo de contenido y prácticas presentes en el discurso. De acuerdo con esta clasificación existen cuando menos siete tipos de discursos sobre los derechos humanos (Cohen, 1994: 7-25).

i) Diplomático. Sus orígenes históricos se encuentran en los movimientos de derechos humanos supranacionales como los de la Organización de la Naciones Unidas, Organización de Estados Iberoamericanos, Unión Europea, etcétera.

ii) Legalista. Con frecuencia similar al anterior, se diferencia porque su enfoque es estrictamente legal e intenta dar forma jurídica a la defensa de los derechos humanos en los ámbitos nacional e internacional.

iii) Político-filosófico. Similar en algunos aspectos teóricos generales al discurso legal, su característica principal es que recoge todos aquellos aspectos relacionados con los 'derechos en general'.

iv) Intervencionista. Se genera y se opera fuera de las estructuras oficiales del Estado, y generalmente se basa en el trabajo de las llamadas organizaciones no gubernamentales (ONG), cuyo alcance puede ser internacional, nacional, regional o local.

v) De monitoreo o vigilancia. Se distingue de los otros en tanto que existen organizaciones o individuos dedicados exclusivamente a informar sobre violaciones a los derechos humanos, no ejercen presión sobre los gobiernos ni participan directamente en casos específicos, y su función es informar y contabilizar las violaciones.

vi) Científico social. Aun cuando no existe una disciplina científica que se dedique exclusivamente al estudio de los dere- 
chos humanos, existen diversos conjuntos de literatura que tratan de aprehender cognitivamente estos temas, ya sea de manera descriptiva/empírica o causal/teórica.

vii) Educacional. Busca reforzar los valores de los derechos humanos a través de la educación dirigida al público en general o a grupos específicos, ya sea en escuelas, instituciones o en cualquier otro espacio. Este discurso se autodefine como preventivo y proactivo; más que ser una respuesta reactiva, busca anticiparse para que las violaciones a los derechos humanos no ocurran.

\section{Los discursos de derechos humanos en México}

En México encontramos, en mayor o menor número, ejemplos de cada uno de estos discursos. No obstante, se utilizan fundamentalmente tres de ellos: el diplomático, el legalista y el intervencionista, y en este panorama es notable la ausencia de un discurso científico social.

\subsection{El discurso diplomático}

Este tipo de discurso tiene dos características fundamentales: la primera es que está basado en un compromiso de trabajar por la promoción y la defensa de los derechos humanos partiendo de una comunicación y un conocimiento racional. Para desarrollarse este discurso se requiere información objetiva, precisa, confiable, imparcial, sistematizada y estandarizada. Esta información es necesaria para tomar las decisiones pertinentes para intervenir. Los vehículos utilizados en este proceso son conocidos como comisiones, comisionados, reportes y observadores, entre otros. Dado el alto grado de tecnificación que alcanza este tipo de trabajo, se requiere la participación de profesionales, es decir, personas culturalmente calificadas y dedicadas por completo a estas labores. Debido al alto grado de especialización y el carácter gubernamental de los participantes, este tipo de discurso es monopolio exclusivo de ciertas élites (Cfr. Cohen, 1994: 3-4).

Desde el final de la Segunda Guerra Mundial, México ha hecho uso de este tipo de discurso al participar activamente en diversos organismos internacionales como la ONU y la OEA, y al firmar un sinnúmero de declaraciones, tratados, protocolos y pactos. En lo que se refiere al tema específico de los derechos humanos, México ha firmado y ratificado la Convención Ameri- 
cana sobre Derechos Humanos; la Convención Internacional sobre la Eliminación de todas las Formas de Discriminación Racial; la Convención para la Prevención y Sanción del Delito de Genocidio; la Convención Interamericana para Prevenir y Sancionar la Tortura; la Convención contra la Tortura y Otros Tratos Crueles, Inhumanos o Degradantes; el Pacto de Derechos Civiles y Políticos; el Pacto de Derechos Económicos, Sociales y Culturales y la creación del Tribunal Penal Internacional, entre otros.

\subsection{El discurso legalista}

Con frecuencia este discurso se empalma con el diplomático, en tanto que es a través de éste que los acuerdos internacionales adquieren forma jurídica. El discurso legalista toma por lo general tres vertientes: la primera es la académica, dedicada primordialmente a la exégesis, interpretación y comentario de textos legales como son leyes, decisiones judiciales, convenios y tratados; la segunda es la vertiente profesional que está orientada al trabajo específico de casos, ya sea individuales o colectivos ante los tribunales locales o internacionales; finalmente, está la vertiente constitucional, caracterizada porque su trabajo está orientado a hacer congruente el derecho internacional con el derecho doméstico. En México, ejemplos de este discurso los encontramos en la propia Constitución, en la que se establecen las garantías individuales, en las leyes secundarias como la Ley Federal para Prevenir y Sancionar la Tortura, la Ley de la Comisión Nacional de Derechos Humanos (CNDH), la Ley de la Comisión de Derechos Humanos del Distrito Federal (CDHDF) o las leyes de las comisiones estatales de derechos humanos. De igual manera, los reportes, informes y recomendaciones que estas comisiones generan son parte del discurso legalista.

\subsection{El discurso intervencionista}

Fuera de las estructuras gubernamentales o intergubernamentales existen numerosos organismos que realizan una promoción y defensa de los derechos humanos, al ser entidades que operan fuera de los ámbitos gubernamental o estrictamente privado, han recibido el nombre de organizaciones no gubernamentales. Estas organizaciones varían tanto en tamaño como en forma de organización, van desde las altamente profesionalizadas y con amplios recursos financieros hasta las poco profesionalizadas con 
escasos recursos y apoyadas en el trabajo de voluntarios. Su radio de acción puede ser internacional o exclusivamente local. En México, organizaciones de este tipo comenzaron a surgir en la década de los setenta. Aunque sin levantar la consigna específica de los derechos humanos, su trabajo estaba orientado en la práctica a su defensa y promoción. Precursor de este tipo de organizaciones fue el Comité de Familiares de Presos, Perseguidos y Desaparecidos Políticos EUREKA. El contexto social que dio origen a este y otro tipo de organizaciones, incluidos algunos partidos políticos, estaba caracterizado por una política gubernamental de hostigamiento, represión e incluso aniquilamiento de opositores políticos. La percepción sobre las violaciones a los derechos humanos en México fue ampliándose hasta ser incluidas no sólo violaciones vinculadas con temas directamente políticos sino otras, tales como la situación de minorías, grupos vulnerables, condiciones de las prisiones, deficiencias y arbitrariedades de los sistemas de procuración y administración de justicia. Hoy en día el número de ong que utilizan el discurso de los derechos humanos es cercano a doscientos. ${ }^{1}$

Además de estos organismos no gubernamentales nacionales existen otros de carácter internacional en cuyas actividades México ha jugado un papel central. Por citar un ejemplo, está el caso de Amnistía Internacional (AI). Fundada en Londres, Inglaterra, a mediados de los años cuarenta, esta organización se creó con el objetivo de "contribuir a que se observen en todo el mundo los derechos humanos que establece la Declaración Universal de Derechos Humanos" (Amnistía Internacional, 1995: 327). Desde entonces, AI ha tenido un gran crecimiento, contando con más de un millón de afiliados individuales distribuidos en más de 170 países y con oficinas en 89 de ellos. Las formas de trabajo de AI incluyen la investigación y defensa de casos individuales sobre violaciones a los derechos humanos, visitas de monitoreo a diferentes países y publicación de reportes nacionales o internacionales sobre la situación de los derechos humanos. Con todas, estas formas de trabajo AI ha estado presente en México. Hasta la fecha, AI ha publicado dos reportes exclusivos sobre México. Con el fin de ilustrar el tipo de discurso que maneja esta organización

\footnotetext{
${ }^{1}$ Esta cifra puede estar subestimada. He intentado conseguir, sin éxito, el número de ONG relacionadas con los derechos humanos. La información proporcionada por algunas organizaciones y fuentes gubernamentales difería notablemente. Por esta razón se decidió incluir la cifra de organizaciones participantes en un Foro sobre Derechos Humanos convocado por la Universidad Iberoamericana en septiembre de 1996, al cual asistieron 180 organizaciones.
} 
cito una parte del reporte titulado México: tortura con impunidad donde se señala que: "La tortura continúa siendo endémica en México. Amnistía Internacional piensa que la razón principal por lo que esto ocurre es la casi total impunidad presente en los oficiales encargados de aplicar la ley quienes actúan rutinariamente fuera de la ley sin temor de ser castigados" (Amnesty International, 1991: 1). Este tipo de reportes de AI suelen incluir recomendaciones a los gobiernos; en este caso el documento mencionado hace 16 recomendaciones al gobierno mexicano, y entre ellas destacan: prevenir los arrestos arbitrarios; prevenir la incomunicación de los detenidos; prohibir el uso de confesiones extraídas bajo tortura; investigar todos los reportes sobre tortura; someter a juicio a los torturadores; respetar el derecho internacional y reconocer los procedimientos internacionales para la protección de los derechos humanos.

Los gobiernos, y el de México no es la excepción, consideran el trabajo y las recomendaciones de este tipo de organismos como inaceptables. De ahí que este tipo de discurso reciba la categoría de intervencionista. El discurso de estas organizaciones es considerado intervensionista, en tanto que ningún gobierno ha solicitado su opinión y mucho menos su injerencia en lo que ellos consideran una intromisión en sus asuntos internos. ${ }^{2}$ De ahí que los gobiernos prefieran siempre el uso de los discursos diplomático y legalista, en tanto que son ellos quienes tienen la capacidad de controlarlos y decidir si los llevan a la práctica o no. Con aguda ironía, el antropólogo Leo Kuper ha explicado esta preferencia gubernamental al decir que un supuesto no escrito del discurso diplomático es el siguiente:

El Estado territorial soberano reclama, como una parte integral de su soberanía, el derecho de cometer genocidio o implementar masacres genocidas en contra de la gente bajo su norma, y que las Naciones Unidas para todos los propósitos prácticos, defienden este derecho (citado en Cohen, 1998: 35).

\subsection{El discurso científico social}

Se mencionó con anterioridad que en México es notable la ausencia de un discurso científico-social sobre los derechos huma-

\footnotetext{
${ }^{2}$ En un foro sobre derechos humanos celebrado en Mérida el 29 de noviembre de 1997, Fernando González Salas, subsecretario de Desarrollo Político manifestó el rechazo de la Secretaría de Gobernación a "cualquier injerencia en asuntos internos bajo el pretexto de los derechos humanos, venga de donde venga". La Jornada, 30 de noviembre, 1997 , p. 47.
} 
nos. Aun cuando esta afirmación requiere de una investigación más detallada, se puede corroborar si uno analiza el tipo de publicaciones de la $\mathrm{CNDH}$, hasta hoy la institución con el fondo editorial más grande sobre el tema en el país. De las 221 publicaciones editadas por esta comisión entre 1990 y 1996, sólo 15 de ellas (6 por ciento) entrarían dentro de la categoría de discurso científico social (CNDH, 1997).

Si bien es cierto que no existe una sociología de los derechos humanos, existen muchas vertientes de investigación que han estudiado diversos temas asociados con lo que llamamos violaciones a los derechos humanos. Destaca la sociología del delito, llamada posteriormente sociología de la desviación o del control social. Más recientemente destacan la sociología del castigo (Garland, 1995) y la sociología de la negación (Cohen, 2001). Paralelo a los aportes sociológicos, otras disciplinas han desarrollado importantes marcos conceptuales que sirven para el estudio de las violaciones a los derechos humanos, particularmente la criminología y la victimología.

La característica fundamental del discurso científico social es su intención de estudiar desde perspectivas históricas, teóricas y empíricas las condiciones materiales y culturales en que se producen las ideas, actitudes, valores, prácticas y regulaciones sobre los derechos humanos. En este sentido, los otros seis discursos restantes son sujetos de investigación por parte del discurso científico social.

Con el afán de simplificar y no apartarse del tema central, en este artículo se incluye a la sociología de la desviación dentro del nombre genérico de criminología. ${ }^{3}$ En este artículo, la criminología, más que un discurso homogéneo y lineal de razonamiento, se refiere al conjunto de explicaciones que distintas disciplinas (sociología, sicología, antropología, etcétera) elaboran sobre las causas, consecuencias e ideas que giran en torno al crimen y al castigo. Una vez hecha esta aclaración, a continuación se describen los aportes que la criminología puede hacer al discurso general de los derechos humanos, y en particular a su vertiente del discurso científico social.

${ }^{3}$ Los sociólogos preferimos el término de sociología de la desviación, en tanto que es más inclusivo que el de criminología. Por lo general, la criminología se centra en las relaciones entre la víctima, el victimario y la ley. La sociología, por su parte, considera para su análisis numerosas conductas que socialmente no son catalogadas como delitos, pero que son vistas como 'anormales', 'desviadas', 'peligrosas' o 'amenazantes' y que son sujetas de sanción o escrutinio público, aun sin la necesidad de normas escritas. 


\section{Aportes de la criminología al discurso científico social de los derechos humanos}

Antes de continuar, quisiera compartir con el lector un motivo que llevó a escribir este texto, y sobre todo que implicó relacionar el discurso general de los derechos humanos con el discurso criminológico. Esta vez es una anécdota personal que, siguiendo el consejo de Wright Mills, me atrevo a reseñar en el entendido de que en ocasiones la experiencia personal es susceptible de convertirse en conocimiento social. Como la gran mayoría de los profesionales que suelen pensar que su disciplina es de la mayor relevancia y sin la cual la sociedad padecería terribles calamidades o sufriría de un era de oscurantismo intelectual, pensé que un sociólogo con nociones de criminología podía ser útil al trabajo de una organización no gubernamental dedicada a la promoción y defensa de los derechos humanos. Escribí una carta explicando mi interés por colaborar con una organización; sin embargo, mi petición fue rechazada. Las razones me sorprendieron: se me informó que dado mi perfil de criminólogo yo debería ofrecer mis servicios en una procuraduría o en un juzgado y no en una organización promotora de la defensa de los derechos humanos.

Dejando de lado la parte anecdótica, me gustaría reflexionar sobre el significado de la respuesta. El argumento en que se basó la negativa, y que es ampliamente difundido, supone que la criminología es útil sólo en el ámbito de la procuración o administración de justicia y no en la defensa de los derechos humanos. El propósito de esta segunda parte del trabajo tiene como objetivo de mostrar que este razonamiento es falso y que su elaboración está basada en un desconocimiento de lo que es el discurso criminológico y de lo que éste puede aportar al discurso de los derechos humanos.

El hecho de no relacionar el trabajo de los derechos humanos con la criminología es, en primer lugar, una posición producto de la ignorancia, pero fundamentalmente es un razonamiento producto de las condiciones sociales en que ambos discursos se han producido en México. La criminología ha sido tradicionalmente una disciplina monopolizada por abogados y por lo tanto con un fuerte contenido legal. La mayoría de los estudios criminológicos se basan sobre hechos o problemas relacionados con los sistemas de procuración y administración de justicia, que por otra parte, son quienes históricamente, a través de sus agentes, han sido los principales violadores de derechos humanos. Existe 
por lo tanto dentro de la imaginación popular una asociación negativa entre criminología y violación a los derechos humanos. Se asume a la criminología como una ciencia orientada al perfeccionamiento o mantenimiento del estado de cosas, al servicio del Estado. Por el contrario, el discurso de los derechos humanos tal y como se ha venido desarrollando en México, se ve a sí mismo como un discurso que pretende transformar precisamente el estado de cosas prevaleciente en los sistemas de procuración y administración de justicia, asociándose frecuentemente con otro tipo de acciones reivindicativas como la lucha por la democracia.

Sin embargo, las razones principales por las que el discurso de los derechos humanos ignora el discurso criminológico son más bien de carácter conceptual. Por definición, incluso legal, las violaciones a los derechos humanos sólo pueden ser cometidas por agentes del Estado (policías, jueces, funcionarios públicos, etc.). Así, cuando un ciudadano inflige un daño corporal a otro ciudadano, legalmente no podemos describir el hecho como tortura, sino que tendríamos que clasificarlo como el delito de lesiones. El caso cambia cuando las lesiones son infligidas por un agente del Estado, entonces se autoriza a hablar de tortura. Si analizamos con cuidado este ejemplo vemos que la misma conducta (que una persona provoque daño corporal a otra) es tipificada de forma diferente dependiendo de quién sea el victimario.

En este punto es donde entra la primera aportación de la criminología al discurso de los derechos humanos. Si la conducta es la misma, la pregunta es: ¿’Por qué si aceptamos que la criminología puede explicar los delitos convencionales, no aceptamos que también puede explicar las violaciones a los derechos humanos? La razón por la que no solemos llamar delitos a las violaciones a los derechos humanos es explicada por Cohen (1998: 37) de la siguiente manera:

Precisamente porque esperamos muy poco de las leyes locales e internacionales como sanciones en contra de los graves delitos estatales (en contra de nosotros mismos o de otros ciudadanos), rara vez ubicamos las violaciones a los derechos humanos en términos delictivos.

Siguiendo con este razonamiento, a los secuestros cometidos por agentes del Estado les llamamos desapariciones; a las lesiones, tortura; al homicidio, genocidio y así sucesivamente. Como podemos observar son los mismos hechos sólo que trasformados por cuestiones semánticas, y sobre todo por razones políticas. A quien beneficia este tipo de diferencias conceptuales es precisamente a quienes violan los derechos humanos, y los defensores 
de derechos humanos, al adherirse a esta clasificación, ayudan a perpetuar estas definiciones. La propuesta para superar este escollo es doble. En primer lugar, invitar al lector a considerar las violaciones a los derechos humanos como delitos. En segundo lugar, invitarlo a analizar y comprender desde el discurso de la criminología las conductas desviadas de los agentes estatales, particularmente jueces, ministerios públicos, policías y miembros de las fuerzas armadas. Considerando lo limitado del espacio, se hará mención sólo de dos líneas de investigación criminológica que pueden ser útiles al discurso de los derechos humanos, en especial en su modalidad de discurso científico social: victimología y teoría de la neutralización.

\subsection{Victimología}

Una crítica que solía hacerse con frecuencia a la criminología era que estaba demasiado interesada en el victimario, olvidándose por completo de la víctima. La víctima solía ser el partido olvidado de la pareja criminal. Toda la atención se orientaba a indagar los motivos del ofensor, el tipo de ofensa que había cometido, el castigo que merecía y el propósito del mismo. Sin embargo, esta deficiencia en el discurso criminológico fue corregida con el desarrollo de la victimología. Es conveniente señalar que esta crítica a la criminología es válida también hoy para el discurso de los derechos humanos, aunque en sentido inverso.

Se puede decir que quienes estudian los derechos humanos se han olvidado del estudio del victimario, quien en última instancia comete las violaciones. No obstante, esta deficiencia puede ser corregida haciendo uso de explicaciones y teorías victimológicas. De hecho, en muchos sentidos los estudios sobre víctimas se asemejan al discurso de los derechos humanos, tanto en su objeto de estudio como en los métodos de análisis. Quizás esta similitud sea más evidente con lo que se conoce como victimología radical, que propugna por una inclusión de las víctimas no sólo de delitos sino de fenómenos más amplios, como pueden ser las víctimas de desastres naturales, guerras, persecución política, negligencia de las políticas de Estado en materia de salud o educación (Neuman, 1994: 57).

Veamos con mayor detenimiento cómo puede intervenir la victimología para explicar las violaciones a los derechos humanos, y quizás más importante, cómo explica la inacción de las personas ante estas violaciones. Para iniciar, considérese la si- 
guiente pregunta: ¿Por qué a pesar de que en el país ocurren frecuentes violaciones a los derechos humanos -recuérdese la masacre de Acteal, Chiapas en 1997- no existe una reacción individual o colectiva proporcional a la magnitud de estos hechos? Basándose en diversos estudios empíricos, la respuesta de la victimología a esta pregunta sería que los testigos (directos o indirectos, estos últimos a través de los medios de comunicación) de un delito suelen disociarse a sí mismos de un hecho que conocen o han presenciado, y que por lo general no ayudarán a la víctima o víctimas por una de las siguientes razones:

i) Por una difusión de la responsabilidad. Se espera que otros lo hagan, el supuesto es que si alguien más lo sabe o lo ha presenciado no hay razón para intervenir.

ii) Incapacidad para identificarse con la víctima. La mayoría de las personas sólo actúan o ayudan si simpatizan con las víctimas o si existe una empatía con su sufrimiento. La mayoría sólo actúa si se trata de alguien cercano y parecido culturalmente, que comparte los mismos valores, ideología, creencias, etcétera. Cuando se trata de víctimas políticas, contrarias a la ideología que uno defiende, la victimización suele justificarse con argumentos como éstos: "ellos se lo buscaron”, "hay que acabarlos porque están perjudicando al país”.

iii) Por una incapacidad para concebir una intervención efectiva. Aun cuando se tiene la intención de participar y apoyar a las víctimas, muchas personas ignoran cómo intervenir; otras no participan porque consideran que su esfuerzo es de poca utilidad; otras deciden no participar por el temor de ser sujetos de represalias (Cohen, 1998: 38).

La relevancia de estas explicaciones para los defensores de los derechos humanos es obvia. Si se conocen los motivos que impiden a las personas participar activamente ante la violación de derechos humanos, se pueden diseñar cursos de acción eficaz para transmitir la promoción y defensa de casos particulares, o en general, difundir con mayor impacto y grado de influencia el mensaje de promoción y respeto de los derechos humanos. En cualquier hecho delictivo, la importancia de los testigos ya sea directa $o$ indirecta es fundamental: si la víctima muere ante el victimario, y no hay quien presencie el hecho, éste jamás será conocido. Para que el delito sea castigado se requiere la participación de un tercero; en el caso de las violaciones a los derechos humanos en 
México, ese tercer partido se llama sociedad civil. Sin embargo, y al igual que en los delitos convencionales, no basta que haya testigos: se requiere su participación. De ahí que sea importante indagar las causas que impiden a los mexicanos participar activamente ante las violaciones a los derechos humanos que ellos suelen presenciar o conocer.

\subsection{Teoría de la neutralización}

Una vez hecha la propuesta de estudiar a los testigos (directos o indirectos) de las violaciones a los derechos humanos, pasemos a la propuesta de estudiar a los victimarios. Para ello recurriremos al enfoque criminológico conocido como teoría de la neutralización. Los creadores de este enfoque, Gresham Sykes y David Matza, sostienen que la conducta de los delincuentes, como la mayoría de las conductas sociales, es aprendida en la interacción social y van más allá al afirmar que:

La desaprobación que emerge de las normas internalizadas y de la conformidad de los otros en el medio social es neutralizada, retrotraída o minimizada con antelación. Los controles sociales que sirven para verificar o inhibir patrones motivacionales desviados se hacen inoperantes y el individuo es liberado para delinquir sin serio daño a su imagen. En este sentido, el delincuente se sale con la suya porque si bien sigue aceptando el sistema normativo dominante, condiciona de tal manera sus imperativos que las violaciones son por lo menos 'aceptables', si no 'correctas'. Así, el delincuente representa no una oposición radical a la sociedad respetuosa de la ley, sino algo así como un fracaso en el remordimiento, a menudo alguien a quien se le atribuye el pecado por los otros antes que pecador en sí mismo. Denominamos a estas justificaciones de desviación en la conducta, técnicas de neutralización (Sykes y Matza, 1989: 121).

Aun cuando estas técnicas suelen ser utilizadas por el delincuente común para justificar su conducta, y por el criminólogo para entenderla, Stanley Cohen sugiere que estas mismas técnicas de neutralización son utilizadas por los delincuentes de Estado cuando tratan de justificar las violaciones a los derechos humanos. Este razonamiento es un segundo aporte de la criminología al discurso de los derechos humanos. Veamos cómo utilizan los delincuentes estatales las técnicas de neutralización cuando tratan de justificar las violaciones a los derechos humanos.

i) Negación del daño. Los victimarios suelen argumentar que su intención no era lastimar a la víctima: "sólo le queríamos 
dar una calentadita", "se queja por unos cuantos moretones".

ii) Negación de la víctima. Aquí la responsabilidad del hecho se le atribuye a la víctima: "ellos iniciaron la agresión", "nosotros les dijimos que entregaran las armas, pero empezaron a disparar", "nosotros sólo nos defendimos".

iii) Negación de la responsabilidad. Aunque se reconoce el hecho, se niega la responsabilidad moral bajo el argumento de la obediencia: "yo sólo seguí órdenes”, “yo sólo cumplí con mi deber". Para ofensores individuales como el soldado común, o colectivos como las fuerzas armadas, este es el más evasivo y poderoso mecanismo de negación.

iv) Condena a los condenadores. Consiste en criticar a los acusadores por no ver sus propias culpas. Para el Estado moderno es la técnica más eficaz cuando se trata de proteger su imagen pública: "sí hay violaciones, pero en otros países son más graves", "por qué no se ocupan de los problemas de sus países", "son turistas revolucionarios que en sus países no pueden generar problemas y vienen a crearlos aquî", "sólo quieren desprestigiar al país".

v) Apelación a lealtades superiores. En este caso las violaciones a los derechos humanos se justifican apelando a las más altas causas: al ejército, a la nación, a la revolución, a la patria, a la pureza del Islam, a la libertad.

En conjunto, el uso de estas técnicas de neutralización impulsan la espiral de negación que hace girar el discurso oficial que justifica las violaciones a los derechos humanos. Según Cohen, la negación oficial sigue los siguientes pasos:

Primero se intenta el "eso no pasó" (no hubo tal masacre, nadie fue torturado). Pero cuando los medios, los organismos de derechos humanos y las víctimas muestran que sí está pasando (aquí están las tumbas; tenemos las fotografías; vean los reportes de las autopsias); entonces se tiene que decir que lo que sucedió no fue lo que parece ser, sino que fue algo realmente diferente: "un movimiento de población”, "un daño colateral”, “autodefensa”. Y al final -el subtexto crucial- "lo que pasó, como haya sido, fue completamente justificado" (para proteger la seguridad nacional, como parte de la guerra en contra del terrorismo). En resumen: Eso no pasó aquí. Y si pasó, es algo diferente. Incluso, si eso es lo que usted dice que es, eso está justificado (Cohen, 1998: 34). 


\section{Conclusiones}

La propuesta de utilizar elementos del discurso criminológico para fortalecer el discurso científico de los derechos humanos es básicamente de carácter metodológico. Sin embargo, en el fondo también es una propuesta de carácter práctico. En la medida en que los organismos de promoción y defensa de los derechos humanos fundamenten su discurso y sus acciones con argumentos científicos, las probabilidades de influencia serán mayores, tanto en su trabajo con la ciudadanía como en su relación con el gobierno y sus funcionarios. Esta afirmación es válida tanto para organismos gubernamentales como no gubernamentales. La discusión sobre derechos humanos rebasa ampliamente los marcos de referencia teórico-conceptuales de la criminología, y no obstante es clara la importancia de vincular ambos discursos con el afán de avanzar en el conocimiento y en las prácticas de respeto y promoción que sobre este tema se tienen en México.

\section{Bibliografía}

Álvarez H., Luis (1997), "Los derechos humanos en los albores del siglo XIX”, en Revista del Senado de la República, vol. 3, núm. 8, México, julio-septiembre.

Amnesty International (1991), Mexico: torture with impunity, IA Publications, Londres.

Amnistía Internacional (1995), Informe 95, Editorial AI, Madrid.

Comisión Nacional de los Derechos Humanos (1997), Fondo editorial de la CNDH 1990-1996, México.

Cohen, Stanley (2001), States of denial: knowing about atrocities and suffering, Polity Press, Londres.

_ (1998), "Derechos humanos y delitos de Estado: la cultura de la negación", en Trabajo Social, núm. 20, enero-marzo.

- (1994), Denial and acknowledgment: the impact of information on human rights violations, Hebrew University, Israel. 
Garland, David (1995), Punishment and modern society, Clarendon Press, Londres.

Ishay, Micheline R. (ed.) (1997), The Human Rights Reader, Routledge, Nueva York.

Madrazo, Jorge (1997), "Principales iniciativas en favor de los derechos humanos", en Umbral XXI, número especial 4, Universidad Iberoamericana, México.

Neuman, Elías (1994), Victimología: el rol de la víctima en los delitos convencionales y no convencionales, Editorial Universidad, Buenos Aires.

Sykes, Greham y David Matza (1989), “Técnicas de neutralización: una teoría sobre la delincuencia", en Revista Cenipec núm. 12, Caracas.

Enviado: 19 de octubre de 2001 Aceptado: 4 de diciembre de 2001 